
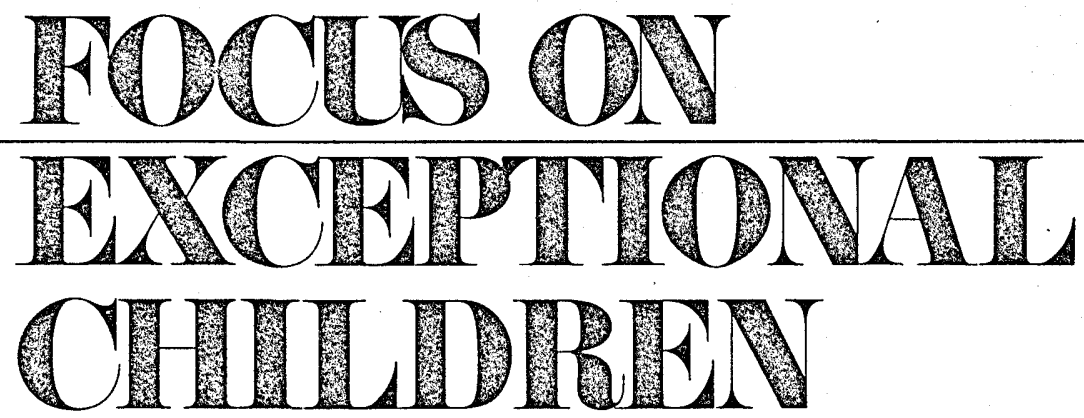

\title{
Curriculum Development:
}

\section{A Process and a Legacy}

\author{
William V. Mayer
}

People talk about the weather, but no one is able to do anything about it. In educational circles, people talk about the curriculum, but few are even trying to do anything about it. Perhaps the curriculum is no more neglected than other facets of the educational enterprise, but the educational literature, filled with papers on objectives, behaviors, learning theories, discipline, basics, and similar topics, reveals a startling lack of papers dealing with curriculum development. The curriculum is frequently regarded as an unchanging feature around which other educational events revolve. Even the dictionary defines curriculum as "a fixed series of studies." This static nature of the curriculum is accurately satirized in The Saber-Tooth Curriculum (Benjamin, 1939).

Curriculum stasis is inexplicable in terms of changes in the world and its human societies. It is explicable only in terms of the interacting components of the educational enterprise. Students training to be teachers are taught how to teach a specific curriculum. Moreover, content and teaching strategies of textbooks either dictate the curriculum or are derived from it. Parents, seeing their children go through the same sequence of study that they themselves experienced, feel that such a curriculum offers a normal and reasonable approach to education. The curriculum prepares students for a sequence of standardized examinations, and the standardized examinations, in turn, reflect the curriculum being taught. Experience, expectation, training, textbooks, and examinations are all linked together to reinforce the status quo and to delay or discourage curriculum change.

\section{A BRIEF HISTORY OF CURRICULUM DEVELOPMENT EFFORTS}

Despite the fact that the curriculum has been largely static, still sharing a majority of features with the curriculum of a century ago, concerns about it have been expressed infrequently. These concerns have usually taken the form of reports from prestigious agencies and committees. An heirloom of such reports is The National Education Association's Committee on Secondary School Studies (also known as the Committee of Ten), chaired by Charles W. Elliott, President of Harvard University. This report, issued in 1893 , made significant recommendations - followed by no evidence that either teaching practices or curriculum structure was significantly altered as a result of the group's recommendations. 
A study by E. G. Dexter in 1906 on the impact of the report of the Committee of Ten noted that little had been achieved by the Committee's recommendations and, indeed, that practice in some instances was running counter to these recommendations. A 1918 report of the Commission on the Reorganization of Secondary Education was designed to orient all courses in the secondary school toward realization of the aims of secondary education stated in the 1893 report. Today's "back-tobasics" advocates would be comforted by knowing that in 1918 one of the cardinal principles of secondary education was to be "command of fundamental processes." The intervening years give evidence that this aim was never achieved in the school curriculum.

In 1927, the report of the Committee on Standards for Use in the Reorganization of the Secondary School Curriculum concerned itself with reorganization of the secondary school curriculum but contained no exciting new developments. By 1932 the Progressive Education Association had renewed a committee examination of the goals of general education in the secondary school and, for the first time, recognized learning theory as a factor in curriculum planning (Commission on Secondary School Curriculum, 1938).

Another shift for the curriculum groups of the 1930s was the acknowledgment of influence by the nature of society and the importance of dealing with student needs and problems. Recommendations that curriculum values

FOCUS ON EXCEPTIONAL CHILDREN (ISSN 0015-5IIX) (USPS 203-360) is published monthly except June, July, and August as a service to teachers, special educators, curriculum specialists, administrators, and those concerned with the special education of exceptional children. This journal is abstracted and indexed in Exceptional Child Education Resources, and is also available in microform from Xerox University Microfilms, Ann Arbor, Michigan. Subscription rates, $\$ 15.00$ per year. Copyright 1982, Love Publishing Company. All rights reserved. Reproduction in whole or part without written permission is prohibited. Printed in the United States of America. Second class postage is paid at Denver, Colorado. POSTMASTER: Send address changes to:

Love Publishing Company

Executive and Editorial Office

1777 South Bellaire Street

Denver, Colorado 80222

Telephone (303) 757-2579

\section{EDITORIAL BOARD}

Edward L. Meyen

University of Kansas

Richard J. Whelan

University of Kansas Medical Center

Carolyn Acheson

Senior Editor
Stanley F. Love

Publisher for personal and social welfare be considered differed from the emphasis of earlier groups, which had primarily emphasized disciplinary content. The 1945 report of the Harvard Committee concerning general education in a free society noted little progress with these recent ideas of curriculum reform. Nor did the Harvard report result in curriculum reform or improved teaching procedures, any more than did the 1893 study chaired by a member of the same institution.

By 1960 enrollment in high school encompassed 70 percent of the 14-17 year age group, whereas at the start of the century only 8.4 percent of that age group was in high school. These 8.5 million students, distributed among 22,000 high schools, presented a range of abilities and interests that the adopted curriculum was simply unable to meet. What had been an academic exercise in curriculum reform over the past 60 years was now a crisis demanding attention. Curriculum recommendations extending back 60 years were reviewed in a new climate in which action on behalf of the nation's and society's problems was the prevailing mood.

No one viewed this attention to the curriculum as a panacea. Teacher preparation, physical plant, policy decisions, administration, and a host of other problems faced education but, for the first time, the curriculum was to be singled out for specific attention on a large scale. Attention to learning theory, to the cutting edge of disciplinary content, and to a matrix of modern pedagogy would provide a more effective delivery system than in the past.

Curriculum efforts of the 1960 s and subsequent decades were to produce new materials in keeping with the best of precepts. Learning theorists were involved. Professionals in the disciplines concerned presented significant content that reflected the current state of the discipline. Teachers were involved to ascertain whether the curriculum innovations could be handled within constraints of the classroom. For the first time, mixed groups of experts in pedagogy, practical classroom situations, disciplinary content, and educational psychology were brought together to deal with the curriculum in a holistic sense, as well as within the boundaries of a given discipline.

\section{FORMALIZATION OF THE MOVEMENT}

Curriculum development began to be formalized, and curriculum development processes started to evolve. A transition from a series of recommendations to an 
integrated plan of development, production, dissemination, and implementation was initiated. The large-scale curriculum development efforts that were instituted in the late 1950 s and carried through the 1960 s and 1970 s demanded organization, coordination, and planning. The investment of significant sums of money in the process of curriculum development resulted not only in a curriculum but in a process that could serve as a model for further work.

Individual curricula met different fates. Some did not survive their field tests. Others made a lasting impact. But perhaps more important than the actual curricula developed was the dignifying of curriculum development through the creation of models and processes in a framework of academic respectability and practical feasibility. The legacy of the curriculum development movements may not be so much the materials they produced as their presentation of the curriculum development process in the form of an organized, useful model.

In the classroom, a teacher's ad hoc decisions to use a specific text, to change a certain laboratory, to include a film, to take a field trip or not, or to supplement or complement classroom work by including additional topical information all represent curriculum modification, if not development. On a slightly larger scale, in the bigger schools of the United States, groups of teachers may decide on curriculum changes and the process may be undertaken by an entire school district, a city, or any of the several units into which schools are functionally divided. At the state level, some states issue guidelines, as in California, and others, such as New York, have not only a syllabus but a statewide examination over the syllabus topics. Thus, the picture of curriculum development within the United States is generally disorganized and varied, where it occurs at all.

The first nationally coordinated curriculum exercises were sponsored by the National Science Foundation, which established curriculum studies primarily in the natural and social sciences. This allowed drawing upon a vast reservoir of talent from throughout the country. Geographic boundaries and administrative units could be ignored in selecting personnel, and a combination of Nobel Prize winners, a ward-winning teachers, and educational researchers could be recognized for their contributions, resulting in a new curriculum synthesis.

\section{Federal Involvement}

In terms of the total educational expenditures in the United States, federal monies for curriculum development were limited but powerful in their effect. These were the first monies ever invested to develop innovative curriculum materials on a national basis. The investment not only led to new curricula and new models for curriculum development, but it also awakened the interest of the educational community in the curriculum, at a great variety of levels and from a great variety of individuals and organizations. Hurd (1978) called the period 1960-1975 a "Golden Age" because of the curriculum development movement and the interest and research it generated.

Unfortunately, the curriculum development movement of this period was also hamstrung by administrative timidity and a lack of understanding of what efforts would be required to gain acceptance for truly innovative curricula. The problems of moving a curriculum are similar to those of moving a graveyard - tradition and inertia oppose both, and the energy required to overcome the tradition and inertia is inordinately large.

Although a cadre of teachers gained experience through the field-testing activities of each curriculum study, this group was always limited in numbers. No curriculum development effort funded by the federal government supported its materials sufficiently to ensure that they were established on a sound, competitive basis. The rationale of placing federal monies in curriculum development but withholding federal support for disseminating information and implementing these progra ms in schools has never been adequately explained. If the government had feared charges of unfair competition or federal encroachment on local school autonomy, it probably should never have entered the curriculum development field in the first place. Nevertheless, having entered it, and initially withstanding these unfair charges, federal agencies acted like the mother who, having given birth to a child, laid it on a stranger's doorstep, wishing nothing more to do with it. One can only speculate that if sufficient funding had been made available for implementing and disseminating federallysponsored curriculum developments, the school curriculum might look much different today than it does under the conception and abandonment approach that characterized the federal curriculum efforts.

\section{The MACOS Program}

A classic case of federal fear of involvement was that of MACOS - Man: A Course of Study - a social science curriculum developed under grants from the National Science Foundation. The MACOS program was prepared, field-tested, revised, and ultimately offered for commercial publication. In the 1,700 or so 
schools in which it was adopted, it worked well but came under fire from militant school critics, with some aid from the commerical publishing industry. Many of the criticisms of the program, which received wide publicity in the press, were either deliberately or unconsciously misleading. In any case, the hulabaloo raised about MACOS drowned out the rational voices that attempted to explain the program. Not surprisingly, the granting agency was silent in the face of negative publicity, seeming to prefer a mea culpa role to a defense of an innovative, contributory program.

That the MACOS program could be so viciously and unfairly attacked without any consequential defense had a markedly negative effect on the acceptance of federally-funded curriculum programs. First of all, it had a negative effect on curriculum development in general. Second, it created new perturbations within the publishing industry. Individual publishers became increasingly reluctant to sponser publication of innovative curriculum materials. No publisher wished to be subjected to attacks, no matter how ill-founded, on any of its programs. This concern was larger than the possible negative image of a single program; the publisher's entire product line might become suspect if the publisher were criticized in the public press for programs stigmatized as either immoral or un-American. Thus, commercial publishers who had originally welcomed the products of federally-funded curriculum studies as tested programs, produced under impeccable academic and pedagogic auspices, came to view such products with suspicion.

\section{Implications of the Formalization Movement}

Despite the politics of curriculum development as revealed by the MACOS incident, I agree with Paul Hurd that the decades of the 1960s and 1970s were indeed a uniquely active period in education. More ferment and involvement occurred, and more innovative products actually reached the classrooms, than at any other time in the history of the American education. Not only was this a unique phenomenon in the United States, but it was unique throughout the world. As one result, many federally-funded curriculum programs were adapted and translated into other languages. The BSCS programs with which I have been associated, for example, have been adapted for use in more than 60 countries and translated into more than 19 languages. No educational movement has spread so widely or so rapidly. The biological curriculum alone has been changed globally because of the American initiative in curriculum development.

\section{A MODEL FOR THE CURRICULUM DEVELOPMENT PROCESS}

The legacy of the curriculum development process itself survives in many models, or as a number of variations on the process developed as each curriculum group strove to formalize its procedures. Some of the models are summarized in Planning Curriculum Development, with Examples from Projects for the Mentally Retarded (Mayer, 1975). Others are reported in each curriculum project's development and evaluation reports. Space prohibits recapitulation of the curriculum development patterns of a wide variety of projects, so I will speak only about the one with which I am most familiar. This process has been summarized by Callahan (1976) and delineated further by Mayer (1976).

A curriculum is approached first of all by ascertaining the status of the discipline, its past and its future directions. Second, present and future needs are determined. This needs assessment considers the delivery system in terms of its effectiveness in communicating the content and techniques of a discipline. It considers the teachers' abilities, schools' facilities, students' needs, community desires, parents' expectations, and the social changes with which today's students are likely to be confronted when they operate as tomorrow's citizens. With the knowledge of what is being done and a good idea of what should be done, those conducting the curriculum investigation can begin to plan the curriculum framework.

A systems-design approach enables curriculum developers to identify resources, personnel, processes, and activities associated with specific stages of curriculum development and to evaluate these in a formative fashion. The process may be analyzed by the use of a transformation-operation (black box) systems model incorporating a storage unit. The symbols used in one such systems model are illustrated in Figure 1, where different geometric shapes are used to delineate "Begin," "Input," "Processing," "Output," and "Store." The latter four symbols are used to identify the activity throughout the model.

A typical model used by BSCS to describe and analyze curriculum development consists of 12 stages as presented in Figure 2. This model represents a descending hierarchy of sequential stages related to producing curriculum materials. Note that evaluation is built into the curriculum plan at an early stage rather than being added on at the end, where it can be of no use in the formative design. Two field tests are planned, and revisions are made according to the feedback.

No timeline is indicated, although the process normally requires a year for each field test, feedback, 


\section{FIGURE 1 \\ General Systems Model}

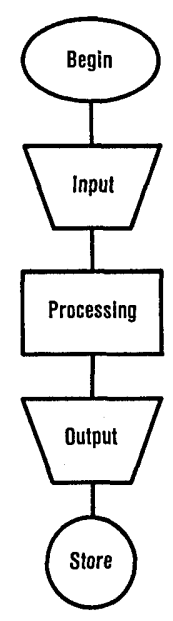

evaluation, and revision. Thus, an extensive curriculum revision minimally takes two years from inception of the plan to delivery of materials to a publisher. The time, however, is a function of the task. Minor revisions can be accomplished in as little as six months. On the other hand, the large-scale, completely innovative initial program of BSCS began with formation of the study in 1958 and was completed in 1963, with the first commercial release of materials.

For illustrative purposes, each of eight stages in figure 2 has been further delineated in other figures. Only stages $8,9,10$, and 11 recycle earlier components of the process. These are not separately illustrated. For example, Stage 8 follows a sequence similar to Stage 3, with the addition of the stored information regarding recommendations for curriculum change. Stage 9 is a repeat of Stage 5 , with the addition of the changes derived from the first teacher orientation program. Stage 10 repeats Stage 6, and Stage 11 repeats Stage 7.

Stage 1, Planning the Curriculum Framework, is elaborated in Figure 3 and shows the curriculum planning process as a collegial one in which the development staff is guided by an advisory board, specialists in the discipline concerned, learning theorists, and the population to whom the curriculum is directed. The general objectives for which the curriculum is to be developed must be clearly delineated and the basic curriculum design established - whether the curriculum is to consist of a textbook, a series of laboratory exercises, a guide for teachers, a resource book, or is to be supported by supplementary materials and demand multimedia approaches. All this must be ascertained early so that the finished curriculum will be an integrated whole. The
Stage 1 process results in the curriculum orientation, goals, and objectives that will guide the entire process.

Evaluation, as indicated in Figure 4, must be built into the curriculum from the beginning so that its results can guide the curriculum development. This formative evaluation, if incorporated at the beginning, uncovers

FIGURE 2

\section{Twelve Stages of Curriculum Development}

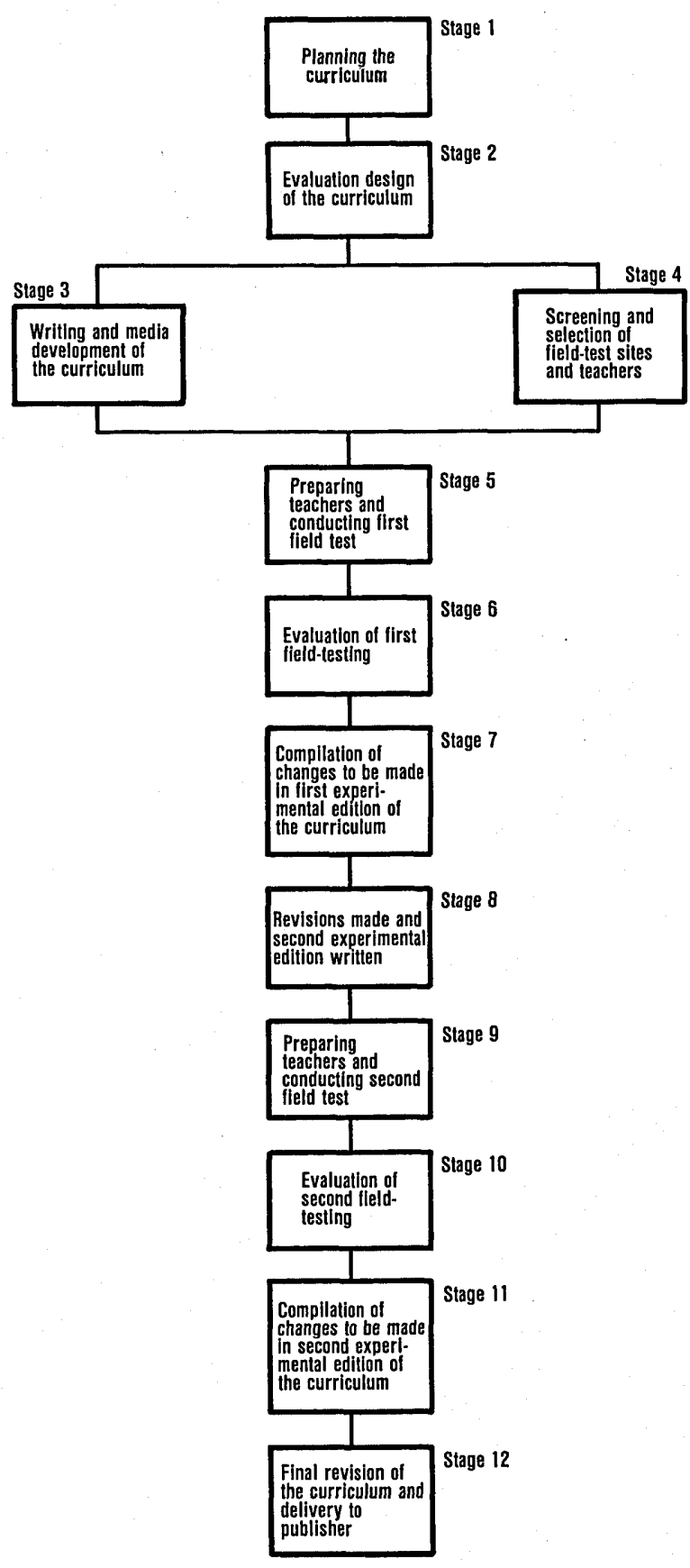




\section{FIGURE 3}

Stage 1 - Planning the Curriculum Framework

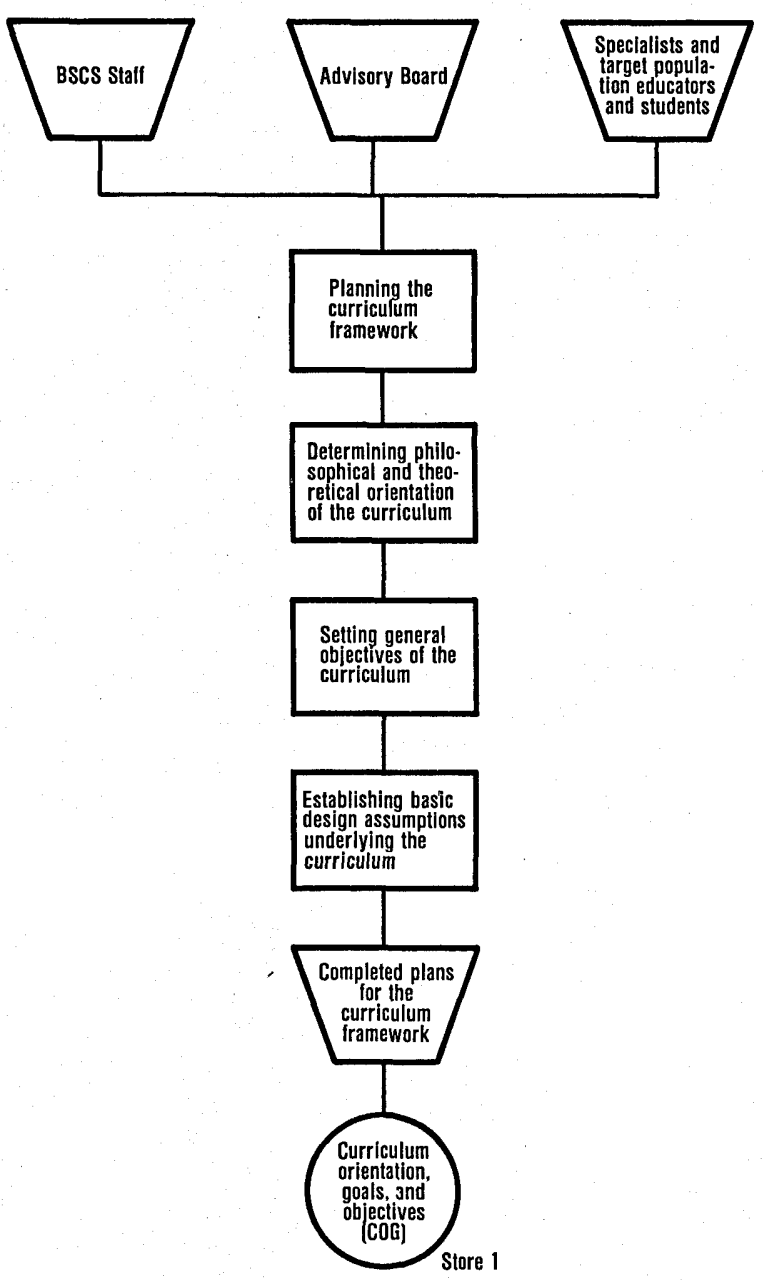

weaknesses and gives direction for improving the entire curriculum effort. Ex post facto summative evaluations have little impact on the actual curriculum, appearing as they do several years after the curriculum is in use.

The evaluation team is usually not the same group that is developing the curriculum, for obvious reasons. This team takes the curriculum orientation goals and objectives and develops an evaluation design and data collection technique that will determine whether or not the curriculum meets its own desideratum. The evaluation design and procedures elicited from Stage 2, together with the curriculum orientation goals and objectives, feed into the major effort of formulating and writing the experimental curriculum in Stage 3.

Stage 3, illustrated in Figure 5, is what most people think of as curriculum development. This is usually the

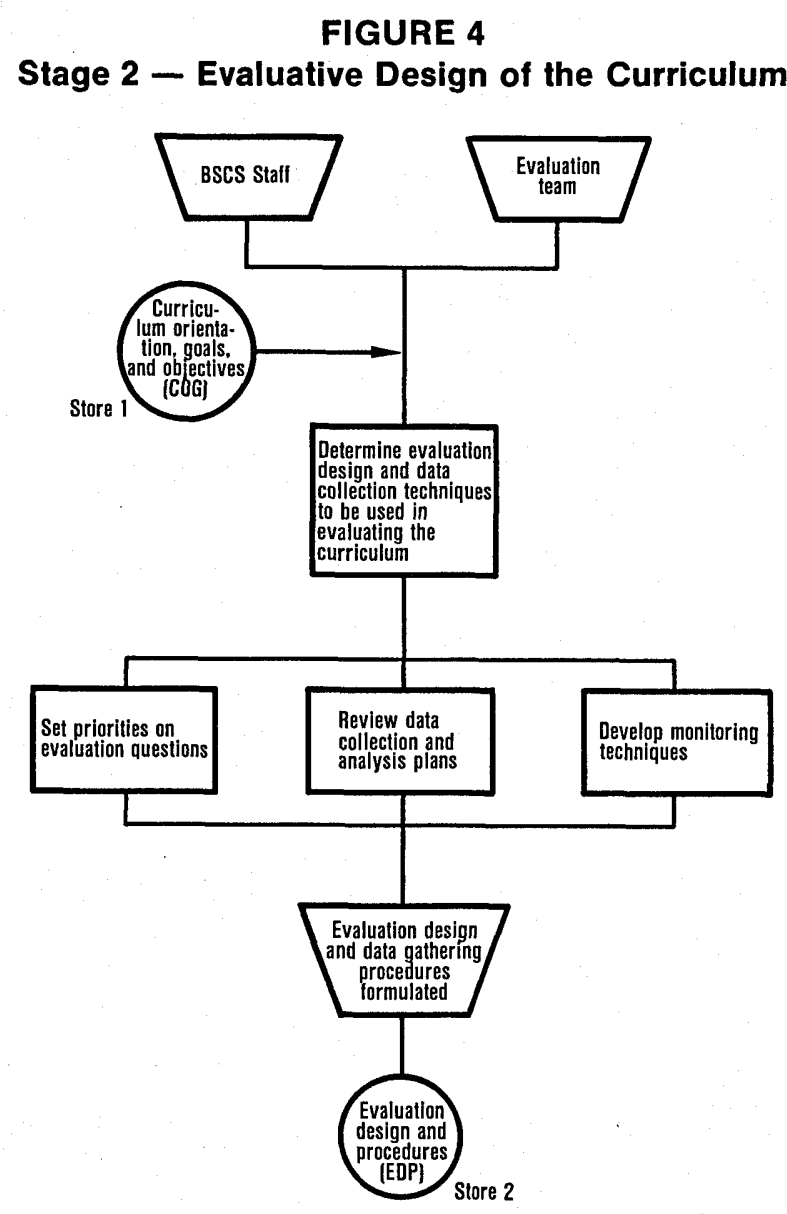

biggest, busiest, and most complex stage, and thus tends to overshadow the other efforts - which are equally important. At this stage the content is selected and translated into forms that will constitute the curriculum. If no media accompany the curriculum, the stages of media development are eliminated; the model is altered to meet this situation.

The output of Stage 3 is an experimental curriculum to be placed in the hands of field-test teachers. To do this, field-test teachers and school sites must be screened and selected. Figure 6 delineates that process - Stage 4 . Because these schools and teachers will be providing the feedback on the experimental materials, they should represent a cross-section of the target population. The broader the field-test sample, the more representative it can be - and on a national basis geographic representation becomes exceptionally important. Also, urban, suburban, and rural schools stand to benefit, as well as schools with low budgets, schools with high budgets, big schools, little schools, inner-city schools, and specialty schools. Of course, the field-test population should conconsist of students of the age and grade level to which 
FIGURE 5

Stage 3 - Formulating and Writing the Experimental Curriculum

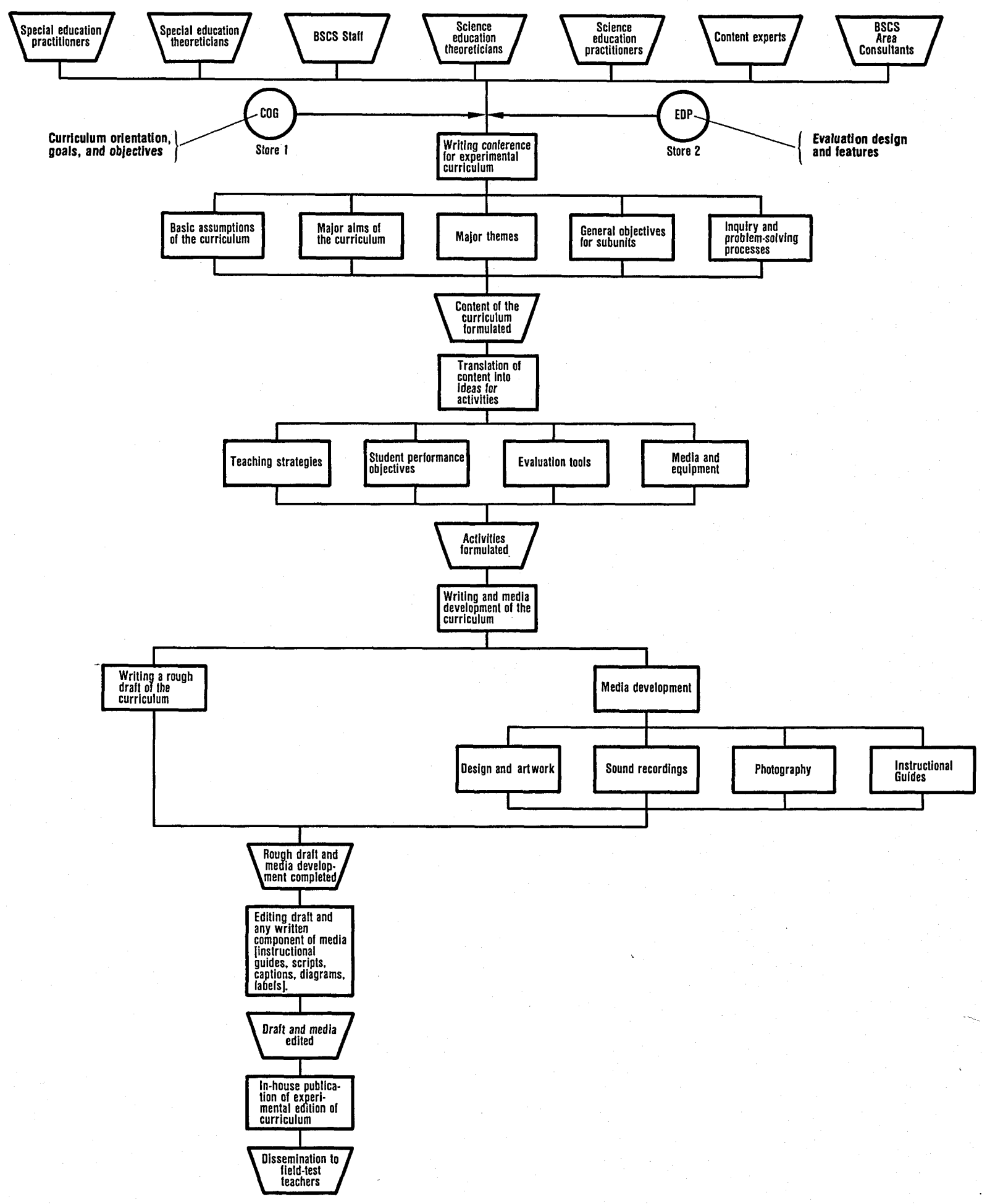


FIGURE 6

Stage 4 - Initial Screening and Selection of Field-Test Teachers and School Sites

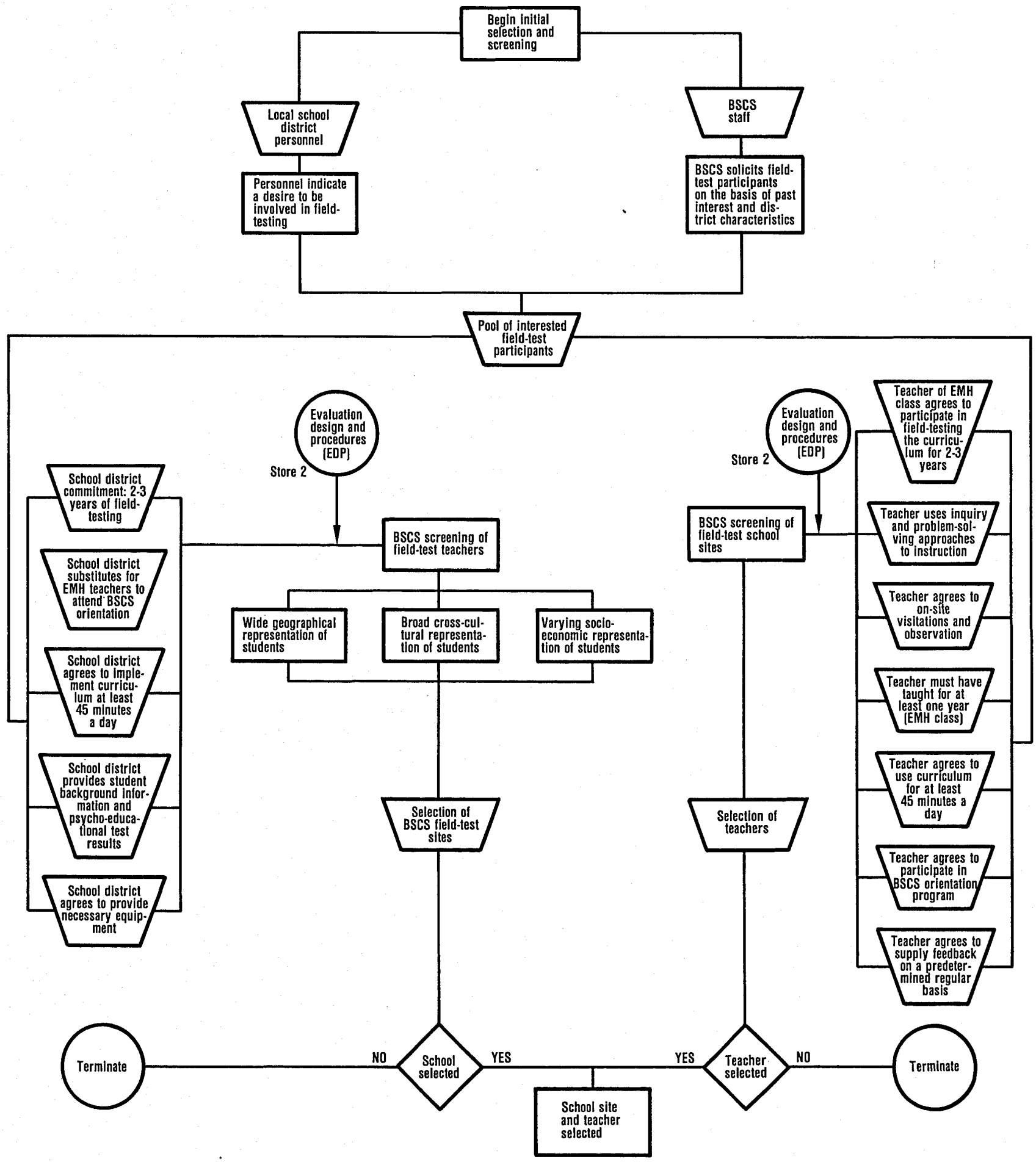


the curriculum is directed, and should be typical of the target population. This means that academically unsuccessful youngsters along with the gifted and talented should generally be exposed to the experimental curriculum.

We know that outstanding teachers can make anything work, but the population of teachers should be representative. An experimental curriculum intended for use with students of varying abilities will be led astray if tested only by outstanding teachers with highability youngsters. Selecting a typical cross-section is not always possible, though, because it depends upon a school administration and a teacher who agree to participate in field-testing for a period that may take several years. The very willingness to become involved in a field-test situation is a self-selecting factor. Field-test teachers, by and large, are risk-takers and have a desire to contribute to innovative programming, thus eliminating teachers who reject change - and who may be the very ones whose concerns could be exceptionally valuable to the developing curriculum. The end product of Stage 4 is the selection of teachers and school sites for the field-testing process.

After the field-test teachers and sites have been selected, Stage 5 in Figure 7 delineates the stages of preparing teachers and conducting the field-testing. An important component at this stage is complete orientation of the teachers to the curriculum to be introduced. Here, introduction of the rationale and the philosophy of the program may be more important than its actual content. Teachers seem to have less difficulty in changing content than in changing methodology, philosophy, or rationale. Obviously, processing items such as, "Use of inquiry and problem-solving methods" in Figure 7 would change if the subject curriculum is not based on an inquiry, problem-solving mode.

Teachers sometimes have difficulty in using diversified student evaluation techniques or methods of recording student performance that may vary from past practice. Therefore, teachers need help in becoming acquainted with new evaluation techniques and in sifting student responses to focus on the more meaningful, contributory ones. After completing the orientation program, the teachers begin teaching and field-testing the experimental curriculum. As a side product, the teachers also provide feedback on the orientation program itself (indicated as Store 3 ), which is used to further refine future orientation programs for teachers.

The field-testing process is worthless unless it leads to usable results. Figure 8 diagrams the components of Stage 6 , dealing with evaluation of field-testing. The various feedback items contribute to evaluation of the

\section{FIGURE 7 \\ Stage 5 - Preparing Teachers and Conducting First Field Test}

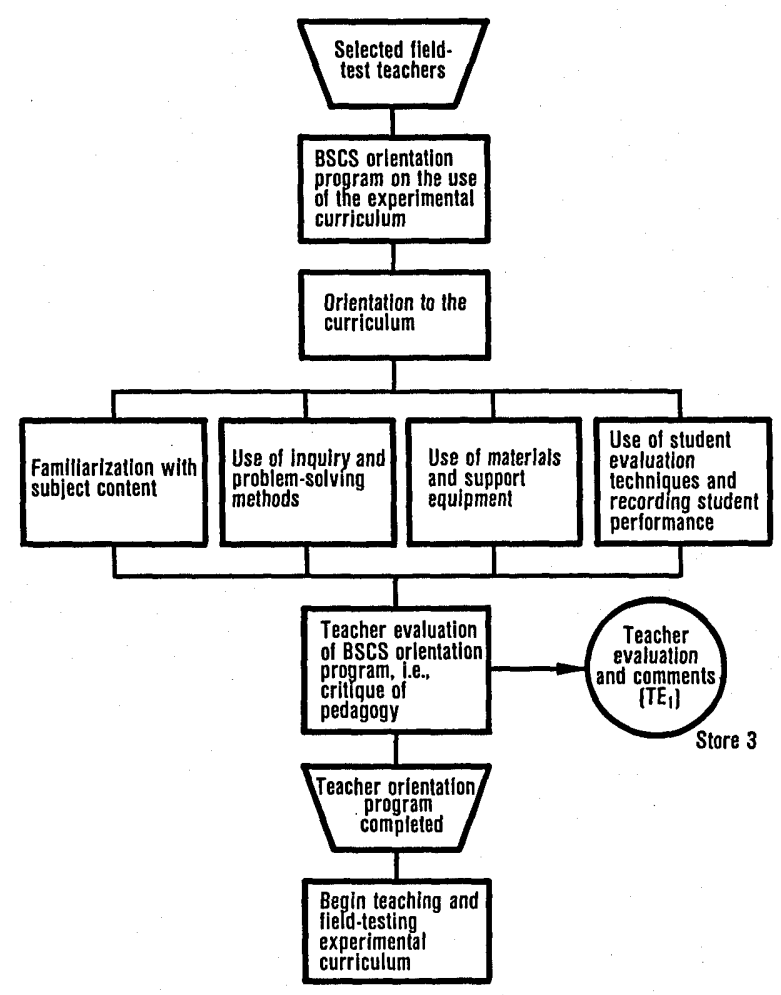

field-tested curriculum, each of whose activities is considered individually and whose components are reviewed in terms of teachability. Together with evaluations of student performance, these evaluations - in which the question constantly asked is, "What does the use of this curriculum do to students?" - provide field-test results as Store 4, which lead to Stage 7 in Figure 9.

In Stage 7 the results of field-testing are subject to the scrutiny of curriculum experts, the advisory board, the evaluation committee, and the local staff, resulting in recommendations for curriculum revision in Stages 8-11 as noted earlier.

The final revision takes place in Stage 12, as shown in Figure 10, and the end product is a curriculum incorporating the input of as many as thousands of teachers and hundreds of thousands of students, together with the input of specialists such as learning theorists, subject matter experts, and those who have evaluated the curriculum for its teachability. What happens to the final revision depends upon the specific arrangements made. The curriculum developers may arrange various ways for materials to reach the target population, but the assumption of Figure 10 is that the materials will be released through the commercial sector and that the 
FIGURE 9

Stage 7 - Compilation of Recommended
Curriculum Changes

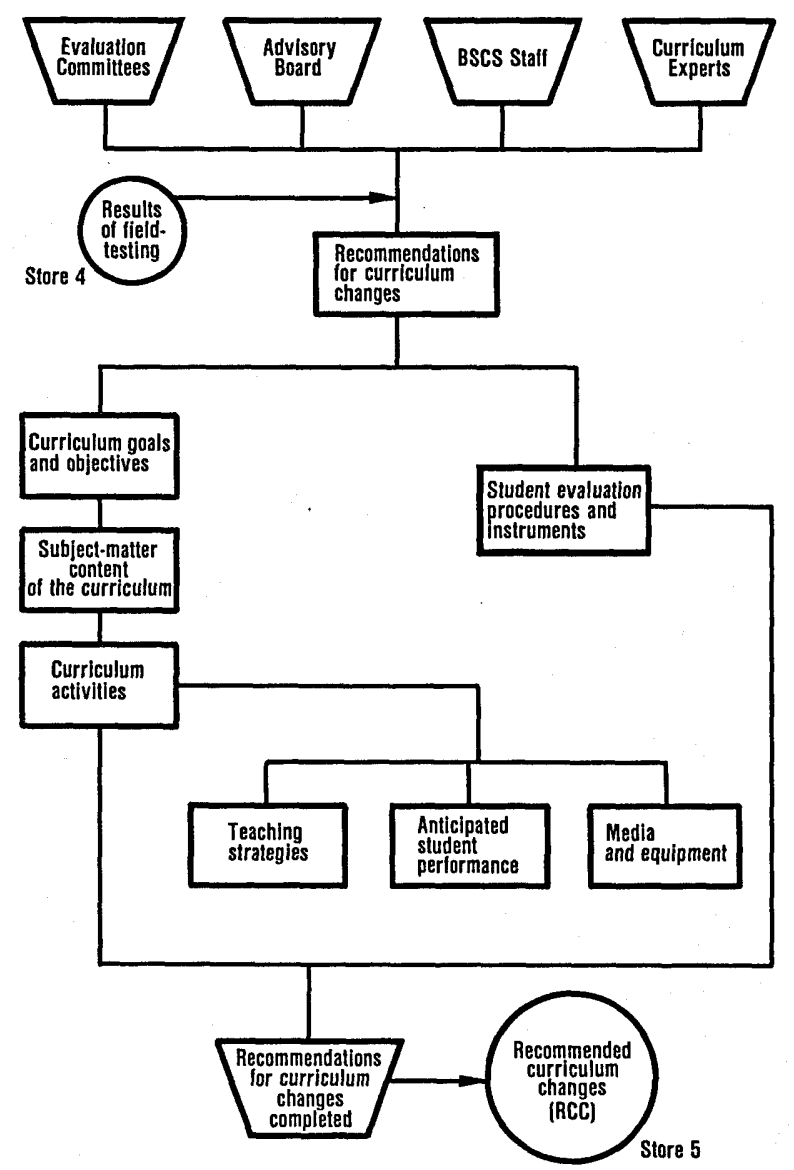

stages followed will vary with the publisher's practices and the developer's desires. If the commercial route is chosen, the production and marketing expertise of a publisher should be involved at an early stage in order for the curriculum to be more of a cooperative enterprise, directed toward successful commercial release.

This systems approach offers a comprehensive view of the elements involved in designing and producing a curriculum. It provides a logical, sequential flow of activities and identifies the components of curriculum development and the various parameters involved in the process. Although the figures illustrate only one model, variations of the process may provide equally viable pathways and products. Most important, the final result offers an alternative to existing curricula for the consideration of educators.

Federal granting agencies now have restricted curriculum development support, as well as the implementation and dissemination activities essential to new

\section{FIGURE 10 \\ Stage 12 - Final Revision and Media Development of the Curriculum}

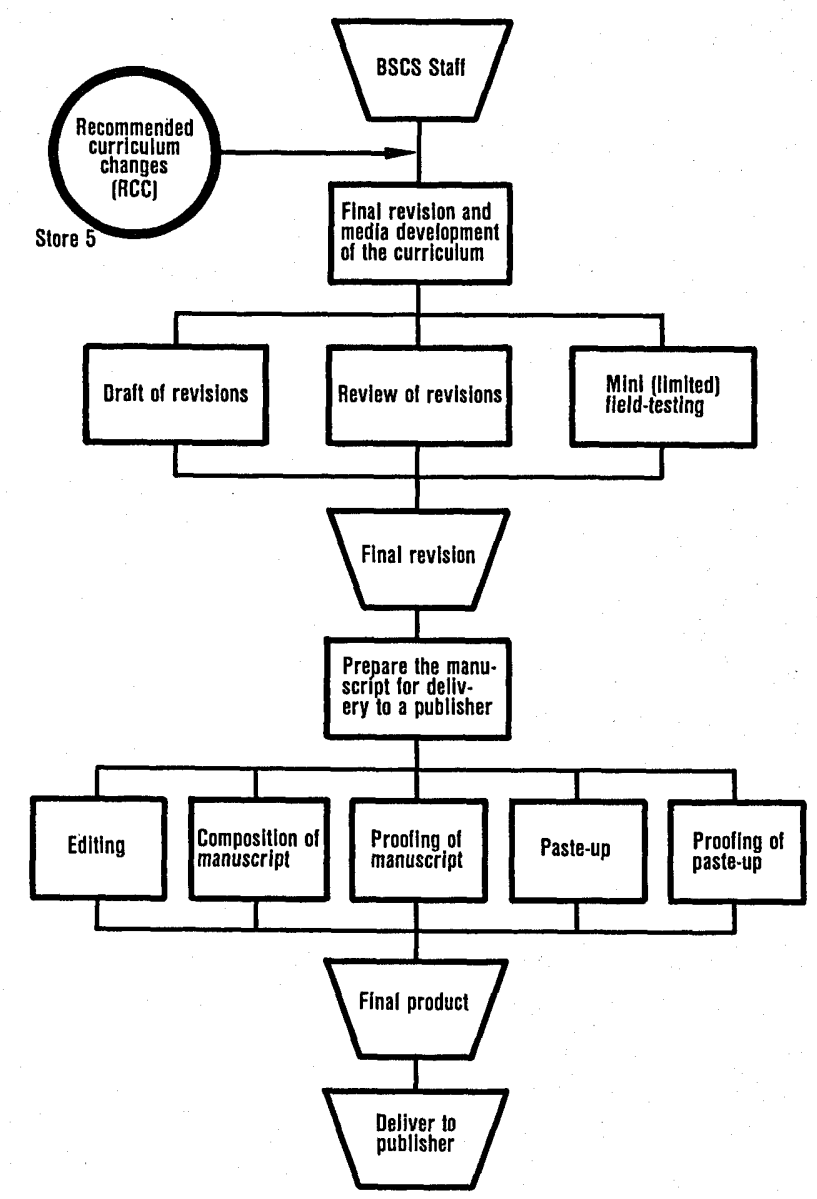

curriculum efforts. This vacuum in curriculum development is being partially filled by private foundations along with publishers and distributors of educational materials who have come to recognize that curriculum studies can indeed improve both content and pedagogy. Indeed, curriculum studies may now have to look for massive future support to the private sector, both foundations and commercial sources.

Curriculum studies have been a powerful force in American education in the past two decades. They have a fine record of accomplishment. The materials developed have changed the format, content, and emphasis of traditional classroom materials. A formal process of curriculum development has been created as a legacy for curriculum workers of the future. Continued curriculum revision is dictated by our changing knowledge and our societal goals. The process of curriculum development will be easier in the years to come because of the efforts of those who refined it during the past two decades. 


\section{REFERENCES}

Benjamin, H. The saber-tooth curriculum. Nèw York: McGraw-Hill, $1939,13,139$.

Callahan, W. P. Formative evaluation report \#5. Assessing student abilities and performance: Year 3. Boulder, CO: BSCS, 1976, pp. 22-30.

Commission on Secondary School Curriculum of the Progressive Education Association. Science in general education. A Report prepared by the Science Committee. New York: Appleton-Century Co., 1938.

Committee on Standards for Use in the Reorganization of the Secondary School Curriculum. Report of the committee on standards for use in the reorganization of secondary school curriculum. North Central Association Quarterly, 1927, 1, 510-514.

\section{ALERT}

\section{NEW BOOKS}

\section{Exceptional Children and Youth: \\ An Introduction (second edition)}

by Edward L. Meyen

The newly revised edition of this comprehensive book covers the field in a timely manner. Entirely new chapters have been added on early childhood intervention and career/vocational education, and the chapter on giftedness has been re-done and expanded to reflect new thinking in that area.

Introductory chapters deal with current generic topics - legislative action and impacts, program planning and IEP implementation, bicultural/minority concerns, issues surrounding testing, assessment, and other areas of interest to educators today. Additional chapters address specific exceptionalities, primarily as they relate to the teacher's role and functions.

The book is highly visually appealing. Use of color, graphic presentations, and readable type make reading a pleasure. To order, contact Love Publishing Company, 1777 S. Bellaire St., Denver, Colorado 80222.

\section{Comparative Reading and Learning Difficulties}

\section{by Lester Tarnopol and Muriel Tarnopol, Editors}

This book provides a comprehensive overview of reading and learning problems in 31 countries, along with in-depth a nalyses of the development and progress of learning disabilities treatment in several of these countries. Comparative studies like this contribute to a better understanding of the variables that comprise literacy.
Commission on the Reorganization of Secondary Education. Cardinal principles of secondary education. Bulletin 1918, No. 35. Washington, DC: Department of Interior, Bureau of Education, 1918.

Dexter, E. G. Ten years influence of the report of the committee of ten. School Review, 1906, 14, 254-269.

Harvard Committee. General education in a free society. Cambridge, MA: Harvard University, 1945.

Hurd, P. The golden age of biological education, 1960-1975. In Biolog.' teachers handbook. New York: John Wiley, 1978, pp. 28-96.

Mayer, W. V.(Ed.). Planning curriculum development, with examples from projects for the mentally retarded. Boulder, CO: BSCS, 1975.

Mayer, W. V. The BSCS process of curriculum development. BSCS Newsletter \#64. Boulder, CO: BSCS, 1976.

National Education Association. Report of the committee on secondary school studies - Report of the committee of ten. Washington, DC: U.S. Bureau of Education, 1893.

Topics of discussion include the various facilities and methods of testing, diagnosis, and remediation; uses of medication; and the directions of ongoing research. Case studies of individual children and programs are included. This is a rich source book that should be of particular interest to speech, hearing, and language clinicians; bilingual educators and researchers; and policy makers. The publisher is D.C. Heath and Company, Lexington, Massachusetts.

\section{UPCOMING MEETINGS}

\section{March 3 - 6, 1982}

Association for Children and Adults with Learning Disabilities

Conrad Hilton Hotel

Chicago, Illinois

\section{March 19 - 23, 1982}

American Educational Research Association New York Hilton Hotel

New York, New York

\section{April 11 - 16, 1982}

Council for Exceptional Children

Albert Thomas Convention Center

Houston, Texas

\section{May 31 - June 4, 1982}

American Association on Mental Deficiency Sheraton-Boston Hotel

Boston, Massachusetts 